\title{
NOVA ESPÉCIE DE CYRTONOTA SPAETH, DO MATO GROSSO, BRASIL (COLEOPTERA, CHRYSOMELIDAE, CASSIDINAE) ${ }^{1}$
}

\author{
Zundir José Buzzi ${ }^{2}$
}

\begin{abstract}
New species of Cyrtonota Spaeth, from Mato Grosso, Brazil (Coleoptera, Chrysomelidae, Cassidinae). A new species of Cyrtonota is described, from Cuiabá, Mato Grosso, Brasil. Its relationships with other species are discussed.

KEY WORDS. Coleoptera, Chrysomelidae, Cassidinae, Cyrtonota, new species
\end{abstract}

BLACKWELDER (1946) cita 50 espécies do gênero Cyrtonota, todas da região Neotropical, mais abundantes no Brasil, Colômbia, Peru, Equador e Argentina. Recentemente foi recebido da Profa. Dra. Rosina Djunko Miyasaki, Universidade Federal de Mato Grosso, Cuiabá, vários cassidíneos, um deles pertencendo ao gênero Cyrtonota. Comparado com os diapositivos das espécies encontradas no The British Museum, com espécimens da Coleção de Entomologia Pe. J.S. Santiago Moure, Curitiba, Paraná e com as descrições das demais espécies, conclui-se tratar de uma nova espécie.

Todas as medidas são dadas em milímetros.

\section{Cyrtonota ricardoi sp.n.}

Figs 1-6

Em vista dorsal, alongada, o comprimento total $(12,5)$ cerca de 1,53 vezes maior que sua maior largura $(8,17)$, na altura do meio dos élitros (Fig. 1). Vista de lado, com curvatura dorsal quase uniforme, levemente mais acentuada na metade posterior (Fig. 2). Em vista frontal (Fig. 5), na altura do meio dos élitros, fortemente convexa. Cor castanho-amarelada.

Cabeça anteriormente com sulco interalveolar, da metade posterior da fronte até anteriormente ao vértice, logo atrás da área interorbital dorsal; entre a fronte e os alvéolos antenais também com forte sulco oblíquo. Vértice e parte das genas pretos. Peças bucais enegrecidas. Fronte subtriangular (Fig. 3), bastante saliente, cerca de 1,8 vezes mais larga que seu comprimento mediano; superfície com pontos e pilosidade esbranquiçada, esparsos. Labro cerca de 2,18 vezes mais largo $(0,72)$ que seu comprimento mediano $(0,34)$; o terço posterior preto e em ângulo com os dois terços anteriores; margem posterior em arco bem acentuado e a anterior com

1) Contribuição número 1020 do Departamento de Zoologia, Universidade Federal do Paraná.

2) Departamento de Zoologia, Universidade Federal do Paraná. Caixa Postal 19020, 81531-990 Curitiba, Paraná, Brasil.

E-mail: zbuzzi@bio.ufpr.br 
forte chanfro mediano. Palpos maxilares com o último artículo preto, bastante encorpado, medindo 0,28 de comprimento por 0,20 de largura; palpos labiais com o artículo apical semelhante ao dos palpos maxilares, medindo 0,28 de comprimento por 0,16 de largura.

Olhos pretos, cerca de 1,74 vezes mais longos $(0,94)$ que sua maior largura $(0,54)$; altura da cabeça $(1,80$ : gena-vértice) cerca de 1,90 vezes maior que seu comprimento. Antenas com 4,60 de comprimento; os cinco artículos basais brilhantes, com pouca pilosidade, de seção subcilíndrica e acastanhados; os demais pretos, de seção elíptica, com densa pilosidade; comprimento do primeiro ao último, medindo, respectivamente, 0,$96 ; 0,24 ; 0,48 ; 0,44 ; 0,40 ; 0,28 ; 0,30 ; 0,30 ; 0,30 ; 0,30$; 0,60; escapo e artículos sete ao último apresentam o maior diâmetro; artículos quatro e cinco apresentam o menor; os últimos cinco antenômeros, no lado interno, com sulco sensorial longitudinal.

Pronoto transversal, cerca de 1,9 vezes mais largo $(6,83)$ que seu comprimento mediano $(3,58)$; superfície finamente pontuada, com quatro manchas pretas transversalmente dispostas, duas sobre o disco, subtriangulares e duas sobre as abas, maiores; pouco mais para trás, lateralmente ao disco, mais próximo da base, duas manchas pequenas, de fraca coloração acinzentada, pouco evidentes; margem anterior levemente emarginada e a posterior, no meio, com suave projeção, um pouco enegrecida; no meio, entre as duas manchas pretas mais centrais, com curto e suave sulco longitudinal, interrompido posteriormente e próximo a projeção mediana, mais forte e aprofundado. bucais.

Prosterno (Fig. 4) de superfície lisa; anteriormente projetado sobre as peças

Escutelo (Fig. 6) preto, subtriangular, ápice largamente arredondado; na base, que fica por debaixo da projeção mediana do pronoto, mais largo $(0,70)$ que seu comprimento mediano $(0,56)$; aos lados com pequena área subtriangular, gradualmente elevada para fora; no sentido do comprimento fortemente convexo, elevando-se mais fortemente da base até pouco além do meio e depois decaindo suavemente.

Mesosterno entre as coxas medianas pouco mais estreito $(0,40)$ que $o$ prosterno e com profunda depressão anterior onde se encaixa o processo prosternal; caindo fortemente para os lados à frente da coxa mediana; ápice do processo mesosternal arredondado.

Élitros forte e densamente pontuados, incluindo as abas laterais, não nitidamente separadas do disco; superfície micro-reticulada e quatro veias longitudinais, esbranquiçadas, visíveis por transparência, a primeira ao longo da sutura, a segunda e terceira, próximas à margem interna e externa da primeira fileira de manchas pretas e a quarta, próxima ao lado mais externo do disco; a base com crenulação fraca na porção mais interna e pouco mais larga que o pronoto; aos lados, da base até próximo ao meio, alargando-se suavemente e após, estreitando-se para o ápice, largamente arredondado; epipleuras com pilosidade esbranquiçada; bordos com fina linha preta com doze manchas, formando três fileiras transversais, a mais anterior com as duas manchas internas, quase elípticas, obliquamente dispostas, as duas manchas mais laterais, estreitas e alongadas para trás a partir do calo umeral até próximo a margem

Revta bras. Zool. 15 (3): 793 - 797, 1998 


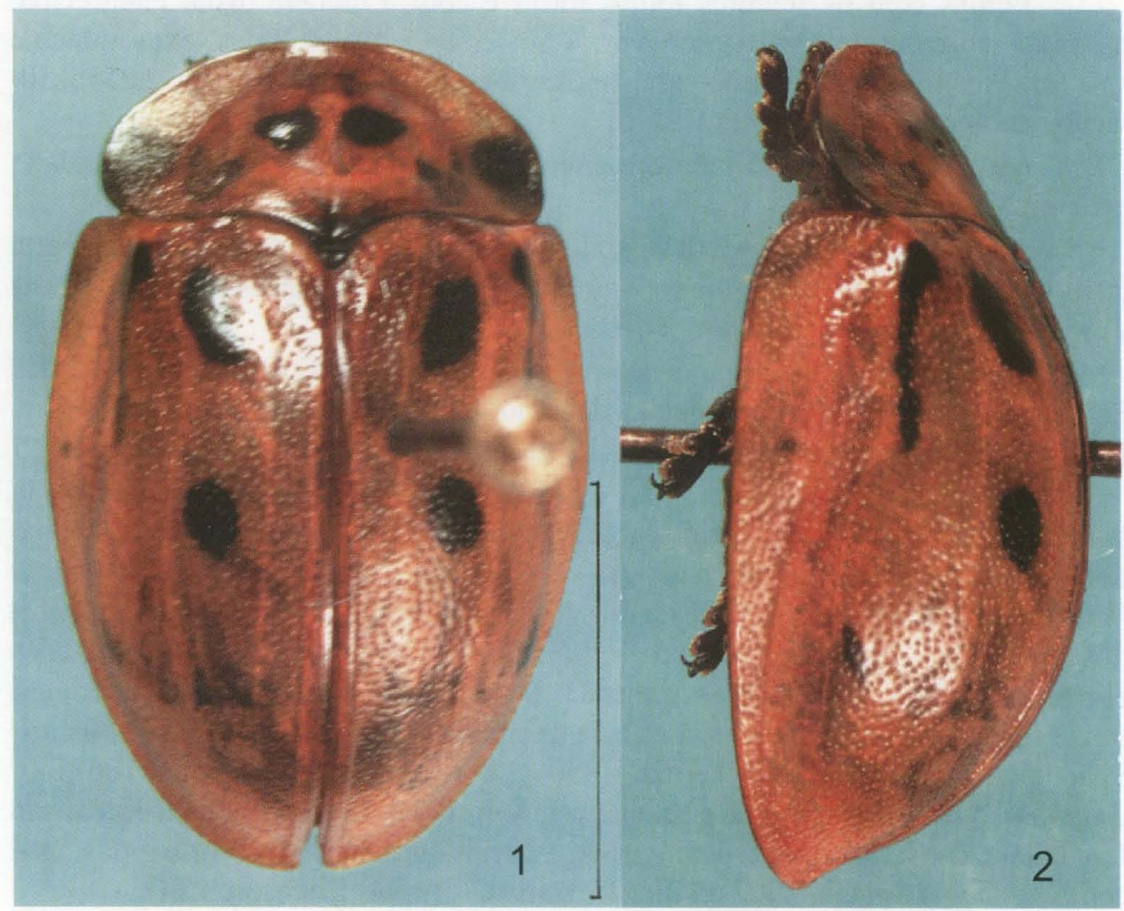

Figs 1-2. Cyrtonota ricardoi sp.n.. (1) Vista dorsal; (2) vista lateral. Escala $=6,25 \mathrm{~mm}$.
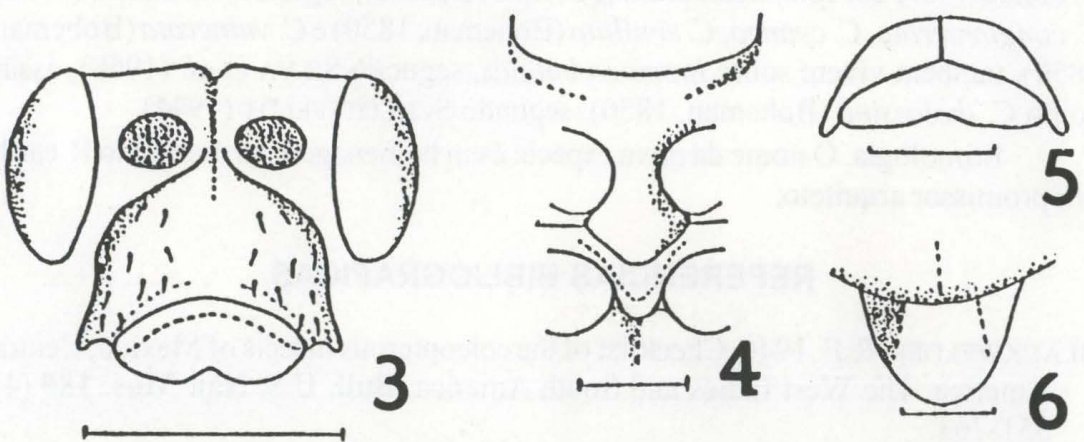

Figs 3-6. Cyrtonota ricardoi sp.n., escalas entre colchetes. (3) Vista parcial e frontal da cabeça [1 mm]; (4) vista parcial do prosterno, mesosterno e metasteno [1 mm]; (5) vista frontal [0,5 $\mathrm{mm}$; (6) escutelo e parte da projeção mediana do pronoto [0,5 $\mathrm{mm}]$.

posterior do terço anterior dos élitros, a fileira transversal mediana, com duas manchas mais internas subarredondadas e as laterais, muito pequenas quase imperceptíveis, sobre as abas; a fileira mais posterior com quatro manchas muito pequenas, todas sobre o disco. 
Pernas com os fêmures muito fortes e com a metade distal enegrecida, medindo do anterior para o posterior: 2,$50 ; 2,58 ; 2,92$; as tíbias, externamente sulcadas, medindo da anterior para a posterior, em milímetros, 2,$33 ; 2,25 ; 2,50$; tarsos com dente da unha muito curto.

Metatórax no meio e anteriormente com forte depressão, mais aprofundado próximo ao mesosterno.

Abdômen com os esternos abdominais posteriormente com faixa preta transversal, mais fraca no primeiro e ausente no último que apresenta forte pilosidade esbranquiçada nas margens externas.

Holótipo. BrasIL, Mato Grosso: Cuiabá, 11-III-1991, Ângela Maria T. dos Santos leg., depositado na Coleção de Entomolgia Pe. Jesus Santiago Moure, Departamento de Zoologia, Universidade Federal do Paraná, Curitiba, Brasil.

Discussão. Cyrtonota ricardoi é facilmente reconhecida pela sua coloração amarelo-acastanhada, pela disposição das manchas pretas tanto do pronoto como dos élitros, pelo aspecto alongado do corpo o que a aproxima de C. adspersa (Boheman, 1850) esta facilmente identificada pela cor preta e pelas aréolas amarelas dos élitros; de C. flavoplagiata Spaeth, 1932 que também é alongada e apresenta os élitros com grandes manchas amarelas. Os élitros de $C$. ricardo $i$ apresentam densa e desordenada pontuação e total ausência de aréolas o que a distingue de $C$. bondari Spaeth, 1928, C. caudata (Boheman, 1850, C. conglomerata (Boheman, 1862), C. cyanea (Linnaeus, 1764) e de C. pavens Spaeth, 1913. Dorsalmente os élitros são fracamente convexos o que a distingue de espécies que apresentam forte gibosidade como C. langei Spaeth, 1902 ou menor, como C. serinus Erichson, 1847.

Ciclo de vida. Nada se conhece sobre o ciclo de vida de Cyrtonota ricardoi. Conhece-se o ciclo de vida de Cyrtonota sexpustulata (Fabricius, 1781) que como C. bondari vive em Ipomoea batatas (Convolvulaceae), segundo MARQUES (1932); C. conglomerata, C. cyanea, C. similata (Boheman, 1850) e C. vulnerata (Boheman, 1850), também vivem sobre Ipomoea batatas, segundo SiLVA et al. (1968), assim como C. thalassina (Boheman, 1850), segundo SCHLOTTFELDT (1944).

Etimologia. O nome da nova espécie é em homenagem ao meu filho Ricardo um promissor arquiteto.

\section{REFERÊNCIAS BIBLIOGRÁFICAS}

BLACKWELDER, R.E. 1946. Checklist of the coleopterous insects of Mexico, Central America. The West Indies and South America. Bull. U.S. Nat. Mus. 185 (4): 551-763.

MARQUES, L. DE A. 1932. Insectos daninhos à batata doce, seus hábitos e os meios de combatel-os. Bolm. Inst. biol. Def. agr., Rio de Janeiro, 45p.

SCHLOTTFELDT, C.S. 1944. Insetos encontrados em plantas cultivadas e comuns. Rev. Ceres, Minas Gerais, 6: 52-65.

Silva, A.G. D’A.; C.R. Gonçalves; D.M. Galvão; A.J.L. Gonçalves; J. Gomes; M. Do N. Silva \& L. DE SimONI. 1968. Quarto Catálogo dos insetos que vivem nas plantas do Brasil. Seus parasitos e predadores. Rio de Janeiro, Ministério da Agricultura, Laboratório Central de Patologia Vegetal, Parte II, 2 
(1), 622p.

SPAETH, F. 1913. Kritische Studien über den Umfang und die Begrenzung mehrerer Cassiden-Gattungen nebst Beschreibung neuer amerikanischen. Arten. Archiv. Naturgeschichte 79 A (6): 126-216.

Recebido em 27.VI.1997; aceito em 23.VIII.1998. 